\title{
Ventriculoarterial septal defect with separate aortic and pulmonary valves, but common ventriculoarterial junction
}

\author{
Victor T. Tsang, FRCS, ${ }^{a}$ Nicholas Kang, FRACS, ${ }^{b}$ Ian Sullivan, FRCP, ${ }^{c}$ Jan Marek, MD, ${ }^{c}$ and \\ Robert H. Anderson, FRCPath, ${ }^{\text {de }}$ London, United Kingdom, and Auckland, New Zealand
}

$\mathrm{T}$ he concepts of aortopulmonary septation along with the formation of the intrapericardial arterial trunks and the subpulmonary infundibulum, both of which are involved in this case, have been extensively reviewed. ${ }^{1-3}$ The unusual malformation of the outflow tracts that we describe here, and which we term a ventriculoarterial septal defect with separate aortic and pulmonary valves, but common ventriculoarterial junction, has not, to the best of our knowledge, previously been documented.

\section{Clinical Summary}

A 7-month-old girl weighing $6.2 \mathrm{~kg}$ was referred for surgery. She had a diagnosis of a doubly committed ventricular septal defect (DcVSD) with fibrous continuity between the leaflets of the aortic and pulmonary valves in the roof of the defect. During surgery, the heart failed to arrest after aortic crossclamping and infusion of cold blood cardioplegic solution via the aortic root. It became apparent that a communication was present between the proximal components of the aorta and the pulmonary trunk at the level of the valvular sinuses. After snaring the branches of the pulmonary trunk, we were able to achieve cardioplegic arrest. The ascending aorta was opened to reveal a window between the sinuses of the aorta and pulmonary trunk proximal to the orifices of the coronary arteries, in addition to DcVSD (Figure 1). The leaflets of the aortic and pulmonary valves were separate from one another, with their facing leaflets in fibrous continuity.

The lesion was distinct from common arterial trunk because there were two separate arterial outlets from the heart, each concordantly connected to the underlying ventricle. It seemed that closure of the interventricular communication would require partition of the leaflet shared between the aortic and pulmonary valves and that, together with closure of the window between the arterial valvular sinuses, this might result in aortic regurgitation. Consequently, we left both the window and the DcVSD open and banded the pulmonary trunk. One week later, we returned the patient to the operating room for debanding of the pulmonary trunk and construction of a Damus-Kaye-Stansel (DKS) anastomosis. We used a bovine pericardial intraventricular baffle to

\footnotetext{
From the Cardiothoracic, ${ }^{\mathrm{a}}$ Cardiology, ${ }^{\mathrm{c}}$ and Cardiac ${ }^{\mathrm{d}}$ Departments, Great Ormond Street Hospital for Children and the Institute of Child Health, London, United Kingdom; and Green Lane Cardiothoracic Unit, Auckland, New Zealand. ${ }^{\mathrm{b}}$

Received for publication June 7, 2007; revisions received July 18, 2007; accepted for publication July 25, 2007.

Address for reprints: Victor T. Tsang, FRCS, Department of Cardiothoracic Surgery, Great Ormond Street Hospital for Children, London WC1N 3JH, United Kingdom (E-mail: tsangv@gosh.nhs.uk).

J Thorac Cardiovasc Surg 2008;135:222-3

$0022-5223 / \$ 34.00$

Copyright $\odot 2008$ by The American Association for Thoracic Surgery doi:10.1016/j.jtcvs.2007.07.056
}

separate the right ventricle from the interventricular communication, thus creating a double outlet from the left ventricle, and placed a 12-mm Contegra conduit (Medtronic, Inc, Minneapolis, Minn) to re-establish continuity from the right ventricle to the pulmonary arteries.

Recovery was uneventful, and she was free of symptoms at 51 months follow-up (Figure 2). The echocardiogram showed good biventricular function. Physiologic tricuspid regurgitation had a peak velocity of $2.7 \mathrm{~m} / \mathrm{s}$, suggesting that right ventricular systolic pressure was about $35 \mathrm{~mm} \mathrm{Hg}$. The Contegra conduit was pulsatile, with a maximum dimension of $24 \mathrm{~mm}$, and there was mild regurgitation across the valve. Flow acceleration was noted at the distal anastomosis of the conduit with a peak velocity of $2.6 \mathrm{~m} / \mathrm{s}$. Good flow was seen into both pulmonary arteries. The cavity of the left ventricle was of normal size, with mild regurgitation across the composite neoaortic valve.

\section{Discussion}

Most malformations involving abnormal development of the outflow tract have been well characterised morphologically and their surgical repair well defined, such as tetralogy of Fallot, double-outlet right ventricle, discordant ventriculoarterial connections, aortopulmonary window, and common arterial trunk.

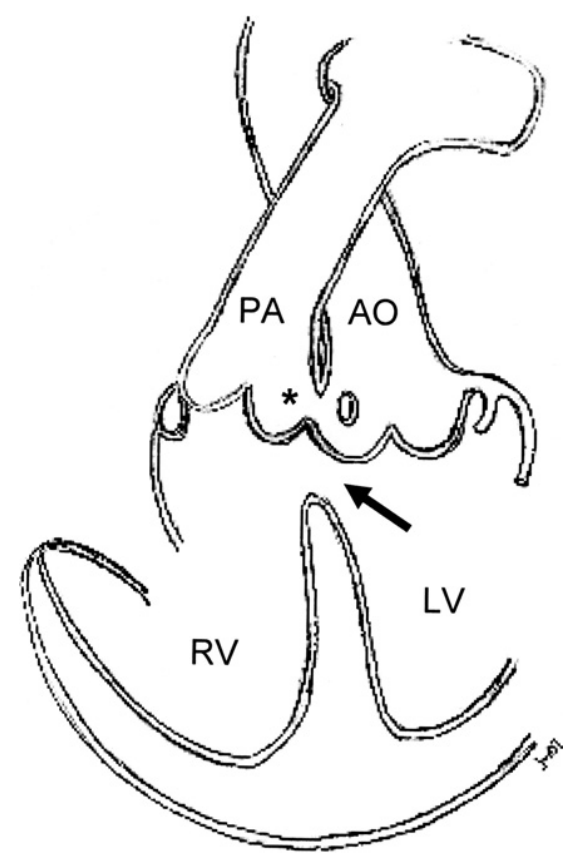

Figure 1. Drawing showing a window* between the sinuses of the aorta and pulmonary trunk proximal to the orifices of the coronary arteries, in addition to the DcVSD (arrow). PA, Pulmonary artery; $A O$, aorta; $R V$, right ventricle; $L V$, left ventricle. 


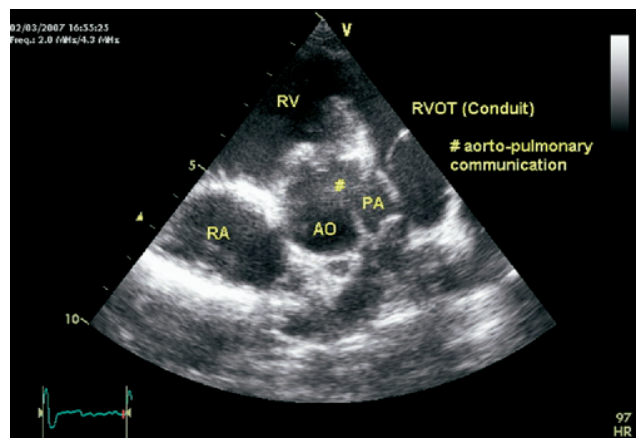

Figure 2. Echocardiogram at 51 months follow-up. RVOT, Right ventricular outflow tract; $R A$, right atrium; $A O$, aorta; $P A$, pulmonary artery; $R V$, right ventricle.

The ventriculoarterial septal defect that we describe in our patient is a combination of a subcoronary window between the aortic and pulmonary valvular sinuses and a DcVSD, with the leaflets of the arterial valves in fibrous continuity and bridging the two defects. The window present between the sinuses of the arterial roots is the consequence of incomplete separation during development of the intermediate part of the developing outflow tract. ${ }^{1,2}$ It would be a mistake to consider the lesion as a deficiency of aortopulmonary septation, not only because, in the normal heart, there is no septum between the aorta and the pulmonary trunk, each possessing its own discrete walls, ${ }^{1,2}$ but also because the intrapericardial trunks in our patient were indeed separate one from the other. The abnormal communication represents inappropriate fusion of the cushions that normally separate the developing aortic and pulmonary valves within their persisting cuff of outflow myocardium. ${ }^{1}$
The DcVSD is the consequence of failure of muscularization of the proximal parts of the outlet cushions, which during normal development become converted to the free-standing subpulmonary infundibulum. The upper margin of such a defect is formed by the conjoined leaflets of the pulmonary and aortic valves, which are at the same level, and are separated only by a thin rim of fibrous tissue. In our patient, the confluence of the aortopulmonary sinusal window and the interventricular communication was spanned by the conjoined leaflets of the arterial valves, just as rarely the bridging leaflets of the valve found in hearts with common atrioventricular junction can be fused to each other, producing separate right and left atrioventricular orifices, yet still float within the atrioventricular septal defect. ${ }^{4}$

The use of a DKS anastomosis to "avoid" creating aortic regurgitation by closure of the DcVSD and subcoronary window is a difficult choice. It would seem that the patient is still at risk for regurgitation with a DKS anastomosis because there is no support for a portion of the aortic valve. We did consider closing the DcVSD and window on the pulmonary side. However, partitioning the outlet valves with only a thin rim of fibrous tissue in continuity is unpredictable in terms of valvular competency. The fallback option of aortic valve substitution in a small infant is rather unfavorable.

\section{References}

1. Anderson RH, Webb S, Brown NA, Lamers W, Moorman A. Development of the heart: (3) Formation of the ventricular outflow tracts, arterial valves, and intrapericardial arterial trunks. Heart. 2003;89:1110-8.

2. Webb S, Qayuum SR, Anderson RH, Lamers WH, Richardson MK. Septation and separation within the outflow tract of the developing heart. J Anat. 2003;202:327-42.

3. Kirby ML. Molecular embryogenesis of the heart. Pediatr Dev Pathol. 2002;5:516-43

4. Anderson RH, Baker EJ, Ho SY, Rigby ML, Ebels T. The morphology and diagnosis of atrioventricular septal defects. Cardiol Young. 1991; 1:290-305.

\section{Papillary muscle realignment for symptomatic left ventricular outflow tract obstruction}

Roosevelt Bryant, III, MD, and Nicholas G. Smedira, MD, Cleveland, Ohio

From the Department of Thoracic and Cardiovascular Surgery, Cleveland Clinic, Cleveland, Ohio.

Received for publication June 30, 2007; accepted for publication Aug 8, 2007.

Address for reprints: Nicholas G. Smedira, MD, Cleveland Clinic, 9500 Euclid Ave/Desk F24, Cleveland, OH 44195 (E-mail: smedirn@ ccf.org).

J Thorac Cardiovasc Surg 2008;135:223-4

0022-5223/ $\$ 34.00$

Copyright $\odot 2008$ by The American Association for Thoracic Surgery doi:10.1016/j.jtcvs.2007.08.034
Video clips are available online.

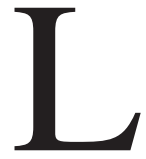

eft ventricular outflow tract obstruction (LVOTO) in hypertrophic cardiomyopathy typically results from proximal septal hypertrophy and systolic anterior motion (SAM) of the anterior mitral leaflet caused by the Venturi effect. ${ }^{1}$ Mitral valve and subvalvular anomalies can also produce LVOTO. ${ }^{2}$ Reported are 2 patients with abnormal orientation of the papillary muscles resulting in LVOTO treated with the technique of transaortic papillary muscle realignment. 